Article

\title{
Development of Ti/Ni Nanolayered Structures to Be a New Candidate for Energy Storage Applications
}

\author{
Osama Saber ${ }^{1,2, *(\mathbb{D})}$, Sajid Ali Ansari ${ }^{1, *(1)}$ and Adil Alshoaibi ${ }^{1(1)}$ \\ 1 Department of Physics, College of Science, King Faisal University, 400 Al-ahsa 31982, Saudi Arabia; \\ adshoaibi@kfu.edu.sa \\ 2 Department of Petroleum Refining, Egyptian Petroleum Research Institute, Nasr City, Cairo 11727, Egypt \\ * Correspondence: osmohamed@kfu.edu.sa (O.S.); sansari@kfu.edu.sa (S.A.A.); Tel.: +966-13-589-9440 (O.S.)
}

Received: 2 September 2020; Accepted: 29 September 2020; Published: 3 October 2020

\begin{abstract}
Development of electrochemical supercapacitor electrode is the best way to improve the performance and conductivity of the alone materials and support energy storage devices. In this work, cyanate anions have used as building blocks to build series of nanolayered materials based on Ti/Ni layered double hydroxides (LDHs). The structural and morphological characteristics of the prepared Ti/Ni LDHs were examined using different techniques. The electrochemical supercapacitive behavior of the prepared LDHs was observed in the three-assembly electrochemical cell. These results showed that the optimized ratio of the nickel and titanium plays an important role to enhance the electrochemical performance of the LDHs. The optimized Ti/Ni LDHs, which has the highest content of titanium, showed the highest specific capacitance $(675 \mathrm{~F} / \mathrm{g})$ value. In this trend, this $\mathrm{LDH}$ also retain a high percentage of the cyclic retention after long cyclic charging-discharging process. The enhanced performance could be due to the double layer structure, enough interplanar distance between the layer, and large number of exposed active site within the double layer structure of the LDHs. Finally, although there are no reports for the electrochemical supercapacitive performance of Ti/Ni LDHs in the literature, it is interesting to produce a new candidate for energy storage applications.
\end{abstract}

Keywords: Ti/Ni LDHs; nanolayered structures; electrochemical capacitive performance; cyclic voltammetry; galvanostatic charge discharge methods

\section{Introduction}

Supercapacitor, known as ultra-capacitor or electrochemical capacitor, considers one of the main keys for developing energy storage devices because of its good safety, long cycling life and high-power performance [1-9]. According to the mechanisms of charge storage, the materials of electrode have been generally classified into three types, including battery-type electrodes with diffusion-controlled Faradaic processes, pseudo-capacitor electrodes with surface electron-transfer processes, and electrochemical double-layer capacitor (EDLC) electrodes with reversible ion adsorption processes. Because of an increasing the demand of electric vehicles, many authors focused on developing the energy storage devices through constructing hybrid supercapacitors to enhance energy densities without the decline of power densities. It was achieved by combining the EDLC electrodes as negative electrodes with the battery-type electrodes as positive electrodes [10,11]. In this trend, the electrochemical performance of supercapacitors was improved through the battery-type electrodes in the terms of energy density, specific capacitance, and working potential window leading to the balance between chemical (high-power output) and physical (high energy output) characteristics [12-16]. Therefore, various battery-type electrode materials were developed using $\mathrm{Fe}_{3} \mathrm{O}_{4}, \mathrm{~V}_{2} \mathrm{O}_{5}, \mathrm{Co}_{3} \mathrm{O}_{4}, \mathrm{NiCo}_{2} \mathrm{~S}_{4}$, and $\mathrm{NiCo}_{2} \mathrm{O}_{4}$ for supercapacitors [17-19]. 
Layered double hydroxides (LDHs) belong to a large family of inorganic nanolayered structures consisting of several nanolayers. These nanolayers, which contain di- and tri-valent cations, act as a cationic host because presence of di- with tri-valent metals produces positive charges. By intercalating anions among these nanolayers, nanolayered structures of LDHs are produced through host-guest interaction [20-22]. Recently, the applications of LDHs in the field of supercapacitors as battery-type materials have been attracted attention because of their high regulation of dominant compositions without the structure transformation. For instance, Ni-Co-Al-LDHs achieved high specific capacitance by Xiao et al. [23], where $2369 \mathrm{~F} / \mathrm{g}$ was observed at a current density of $1 \mathrm{~A} / \mathrm{g}$. In addition, Jagadale et al. reported that the maximum specific capacitance of Co-Mn LDHs was observed at the current density of $0.7 \mathrm{~A} / \mathrm{g}$ and was $1063 \mathrm{~F} / \mathrm{g}$ with $96 \%$ cycling stability for 5000 cycles [24]. Moreover, new opportunities for accelerating ion diffusion processes during Faradaic reactions was attractive through the exchangeable characteristic of interlayer anions among the nanolayers of LDHs host to control the inter-planar spacing and interlayer building block [24].

Although, wide variety of materials has tested for supercapacitors [23-27], Ni-Ti LDHs have seldom been investigated in this field. Ni-Ti-cyanate LDHs have not reported, not even by the latest literature available $[26,27]$. In this trend, the current study focuses on preparation of series of Ni-Ti LDHs. Formation of Ni-Ti LDHs at different reaction times is investigated by different techniques. Furthermore, the effect of the molar ratio of $\mathrm{Ni} / \mathrm{Ti}$ on formation of $\mathrm{LDH}$ structure is examined through intercalation of cyanate anions. The electrochemical behavior of the prepared materials is deeply studied in the field of supercapacitors.

\section{Materials and Methods}

\subsection{Materials}

Nickel (II) chloride hexahydrate, titanium (IV) chloride and urea were acquired from Sigma Aldrich. Nickel (II) chloride hexahydrate powder (SKU 654507) has purity 99.9\%. Titanium tetrachloride liquid (SKU 208566) has purity $99.9 \%$ with density $1.73 \mathrm{~g} / \mathrm{mL}$. Titanium tetrachloride was sensitive for air and strongly dissolved in water with exothermic reaction. Therefore, preparation of the aqueous solution of titanium tetrachloride was carried out in vacuum box. The nickel foam with $1.6 \mathrm{~mm}$ thickness, $346 \mathrm{~g} / \mathrm{m}^{2}$ surface density, $\geq 95 \%$ porosity, and $>99.99 \%$ purity was purchased from MTI Corporation, USA. Typically, an aqueous solution of titanium tetrachloride $(0.024 \mathrm{M})$ was added to urea solution $(1 \mathrm{M})$ to prepare $750 \mathrm{~mL}$ of clear solution. Then, $250 \mathrm{~mL}$ of nickel chloride solution $(0.095 \mathrm{M})$ was mixed with the previous solution under vigorous stirring. The temperature of the reaction was adjusted at $80^{\circ} \mathrm{C}$. The molar ratio of Ni:Ti was 4 . By filtration and washing, the product was dried at room temperature. To study the effect of titanium concentration on Ni-Ti LDHs, the previous process was repeated by changing the molar ratio of Ni:Ti to be 3,4 and 5 . The temperature of the process was adjusted to $80^{\circ} \mathrm{C}$ for $19 \mathrm{~h}$. The sample was labeled here after as Ni-Ti-Y LDHs, where $\mathrm{Y}$ is the Ni/Ti molar ratio.

\subsection{Physical Characterization}

The nanolayerd structure of the prepared materials was studied by Powder X-ray diffraction (XRD) through Rigaku RINT 2200 (Tokyo, Japan). Fourier transform infrared spectroscopy (FTIR) was carried out through Horiba FT-720 (Tokyo, Japan). Thermal analyses (DTG, DTA and TG) were performed using a Seiko SSC 5200 apparatus (Tokyo, Japan). Scanning electron microscopy (SEM) was achieved with a JEOL JSM-6330F, (15 kV/12 mA), Japan.

\subsection{Three Assembly Electrochemical Cell Setup And Electrode Preparation}

The electrochemical performance of the prepared materials was examined in the three-electrode half-cell assembly using Auto lab electrochemical workstation. Platinum sheet assembled in glass rod used as counter electrode (Metrohm), whereas $\mathrm{AgCl} / \mathrm{Ag}$ electrode was used as reference electrode. The $\mathrm{KOH}$ solution was used as electrolytes for the electrochemical measurements. The working 
electrode prepared through making the slurry of the $10 \%$ carbon black, $10 \%$ PVDF, and $80 \%$ active material in the NMP solvent. The above slurry was further coated on the washed nickel foam with the effective area of $1 \mathrm{~cm}^{2}$ and loading of the active material was $\sim 2 \mathrm{mg}$. The coated electrode was further dried in the oven and performance was analyzed using cyclic voltammetry $(\mathrm{CV})$ and Galvanostatic charge discharge methods.

\section{Results and Discussion}

\subsection{Powder X-ray Diffraction}

Figure 1 showed the X-ray diffraction pattern of Ni-Ti-4 LDHs after reaction time $6 \mathrm{~h}$. It revealed non-crystalline structure. By continuing the reaction time to be $8-14 \mathrm{~h}$, one clear peak started to grow at $0.73 \mathrm{~nm}$. Furthermore, weak peaks were observed at $0.37 \mathrm{~nm}$ and $0.27 \mathrm{~nm}$ as shown in Figure 1.

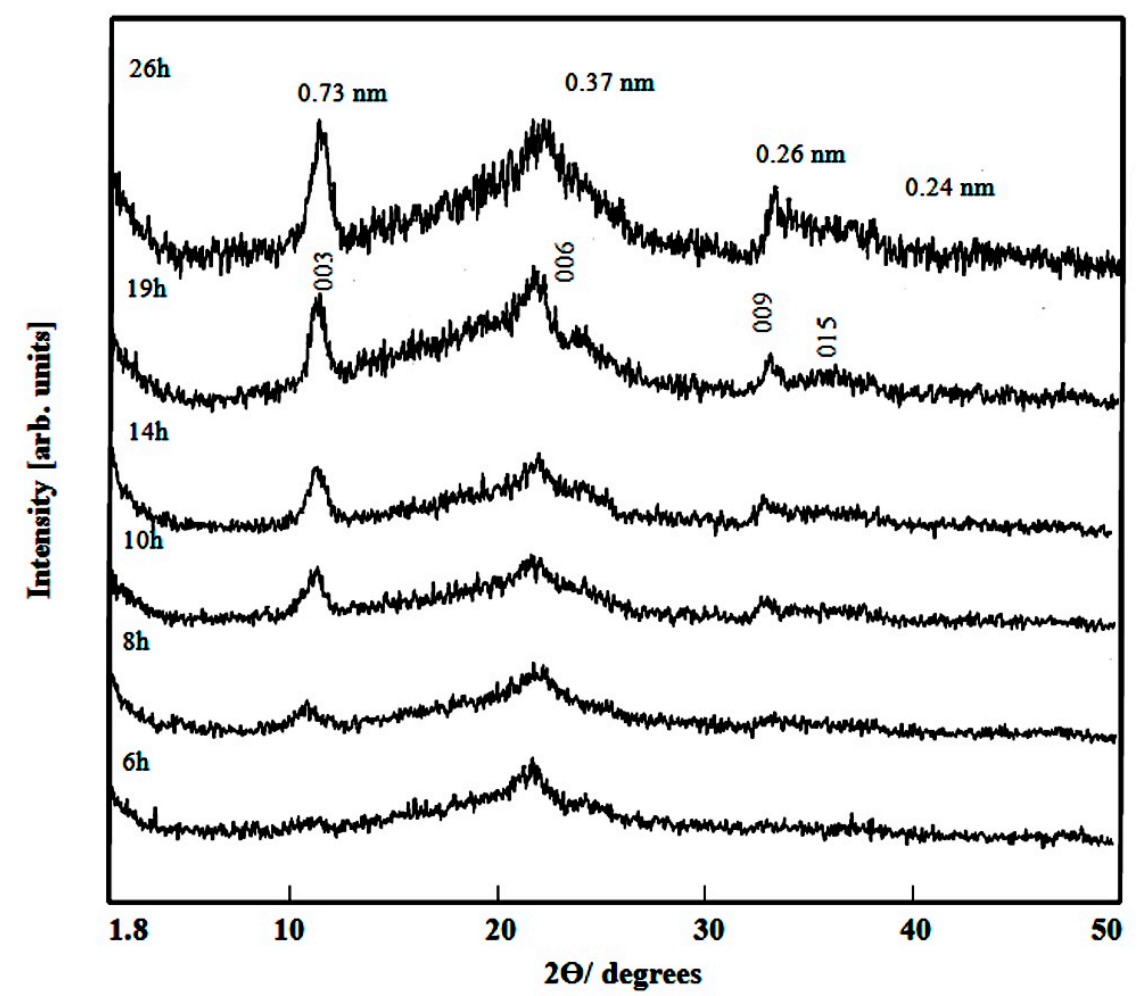

Figure 1. X-ray diffraction of Ni-Ti-4 LDHs at different reaction times.

These peaks are similar to the main peaks of the conventional layered double hydroxides and the natural hydrotalcite. After the reaction time $19-26 \mathrm{~h}$, the X-ray diffraction patterns showed clear peaks at $0.73 \mathrm{~nm}, 0.37 \mathrm{~nm}, 0.26 \mathrm{~nm}$ and $0.24 \mathrm{~nm}$. These peaks agree with the reflections of 003,006 , 009, and 012 planes of LDH structure. The good agreement between the values corresponding to successive diffractions by basal planes, i.e., d003 $=2 \mathrm{~d} 006=3 \mathrm{~d} 009$, reveals nanolayered structures with highly packed stacks of brucite-like layers ordered along axis c. Dimension c is calculated as three times the spacing for planes (003), i.e., $2.19 \mathrm{~nm}$. This $\mathrm{c}$ dimension is lower than that reported for natural and synthetic hydrotalcite, $2.31 \mathrm{~nm}$ [28].

Comparing with the XRD results of the carbonate-LDHs, the interlayered spacing of the prepared product shifted to lower value from $0.76 \mathrm{~nm}$ to $0.73 \mathrm{~nm}$ indicting that the interlayered anions are different from carbonate anions. This value is related to the thickness of the brucite-like layers $(0.48 \mathrm{~nm}$ for hydrotalcite), as well as the size of interlayered anions (and, in some cases, its orientation) and the number of water molecules existing in the interlayer. 
To study the effect of water molecules on the interlayered spacing of Ni-Ti-4 LDHs, the samples were dried at room temperature and measured by XRD. Figure 2 showed the X-ray diffraction patterns of the prepared products after different reaction times. They showed that the interlayered spacing shifted from $0.73 \mathrm{~nm}$ to $0.75 \mathrm{~nm}$ because of presence of more water molecules inside the interlayered spacing. However, the nanolayered structure of the prepared product did not change indicating successive reflections at $0.75 \mathrm{~nm}, 0.38 \mathrm{~nm}$ and $0.26 \mathrm{~nm}$.

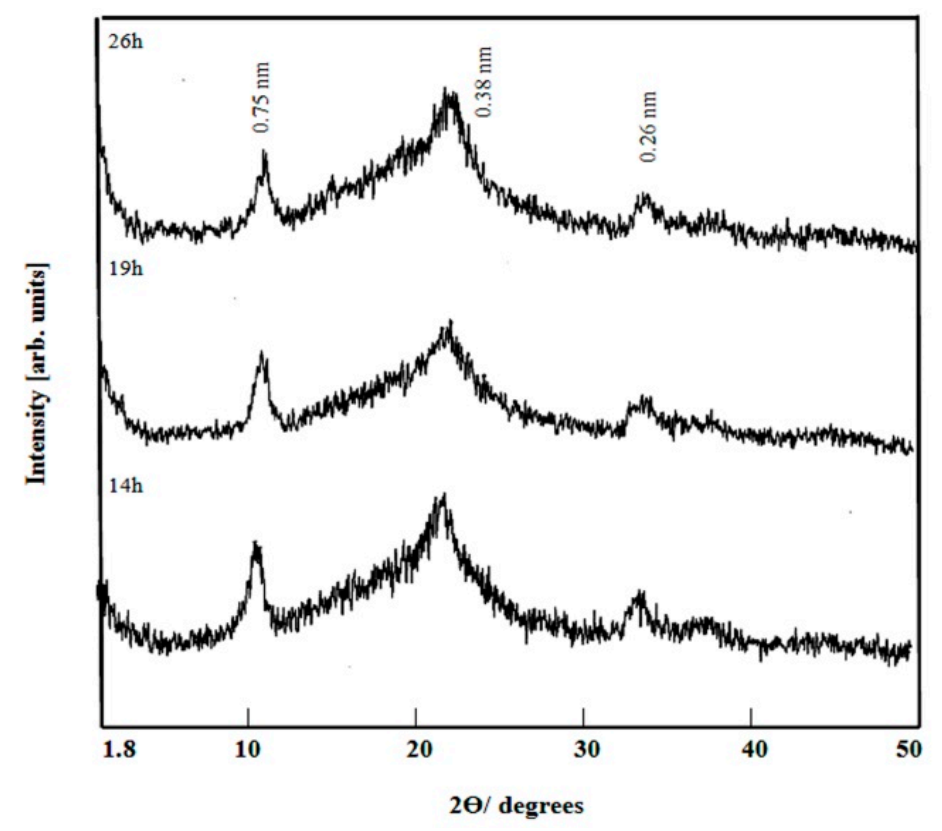

Figure 2. X-ray diffraction of Ni-Ti-4 LDHs at different reaction times and dried at room temperature.

The effect of $\mathrm{Ni} / \mathrm{Ti}$ molar ratio on formation of Ni-Ti LDHs was also investigated as shown in Figure 3. Figure 3 showed that Ni-Ti LDHs are formed with different molar ratios of Ni/Ti; 5, 4 and 3 . The XRD patterns revealed the basal reflections of (003), (006), and (009) planes, which are characteristic of LDHs structure. Also, it can be noted that the nanolayered structures are observed for all samples.

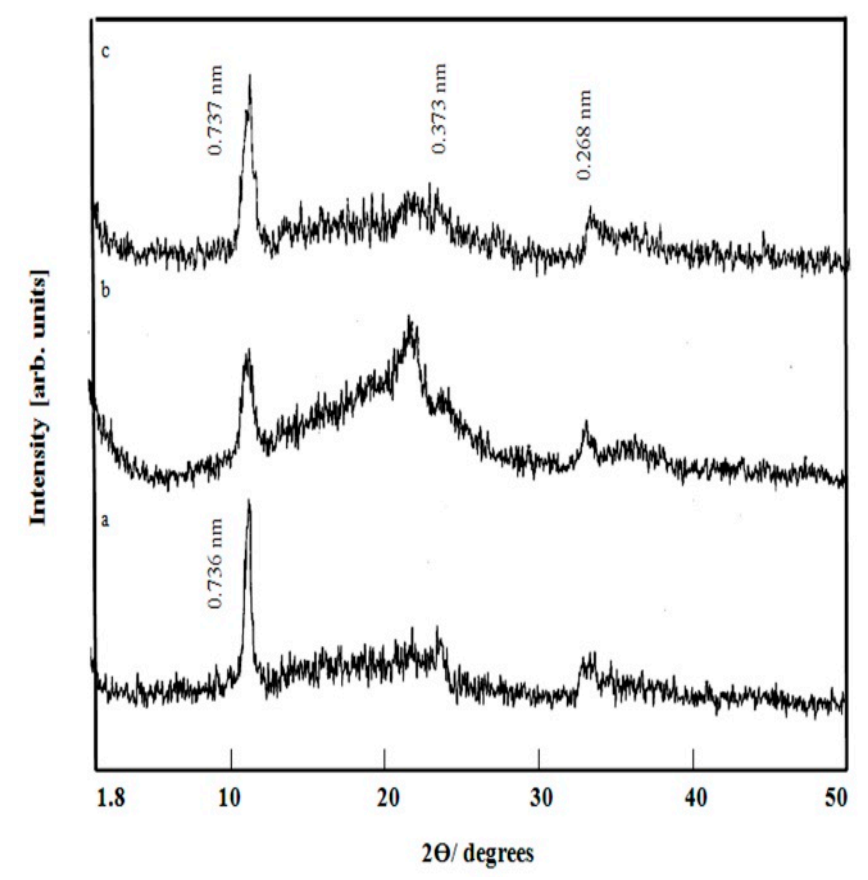

Figure 3. X-ray diffraction of (a) Ni-Ti-5 LDHs, (b) Ni-Ti-4 LDHs and (c) Ni-Ti-3 LDHs. 


\subsection{Fourier Transform Infrared Spectroscopy}

FT-IR technique has used to detect and identify the nature of the functional groups and the interlayered anions of Ni-Ti-4 LDHs as shown in Figure 4. Figure 4 displays the spectra of Ni-Ti LDHs after reaction time $10 \mathrm{~h}$ and $19 \mathrm{~h}$.

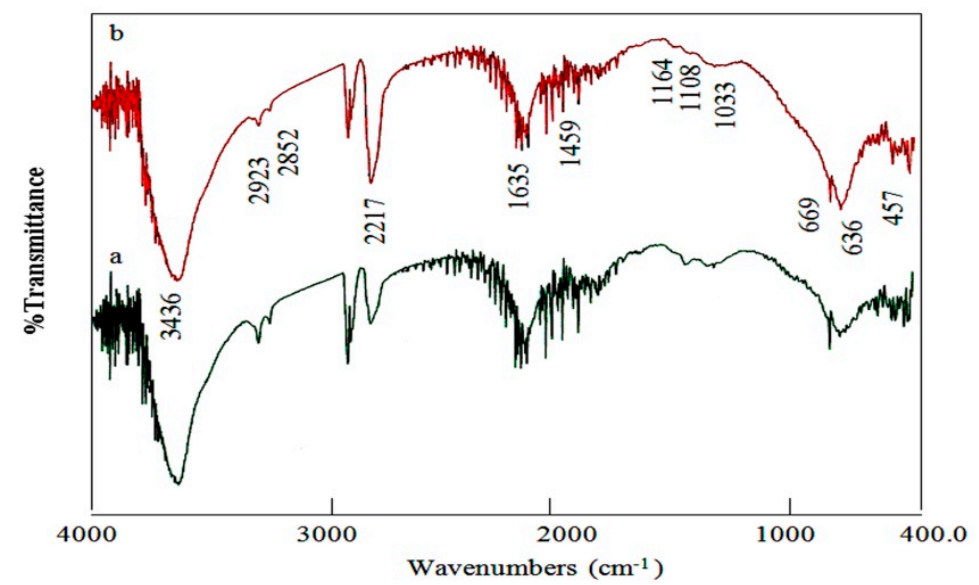

Figure 4. Infrared spectra of Ni-Ti-4 LDHs after reaction times: (a) $10 \mathrm{~h}$ and (b) $19 \mathrm{~h}$.

The vibration of the hydroxyl groups of LDHs was observed at $3436 \mathrm{~cm}^{-1}$ as a broad absorption band. The broadness of the $\mathrm{OH}$ band was due to existence of hydrogen bonds which was confirmed by observing weak bands at $2923 \mathrm{~cm}^{-1}$ and $2852 \mathrm{~cm}^{-1}$ for the $\mathrm{OH}$ stretching mode of the hydrogen bonds to the interlayered anions and water molecules [29]. Furthermore, the bending mode band of water molecules was observed at $1635 \mathrm{~cm}^{-1}$ [29]. The insertion of cyanate and isocyanate anions into the Ni-Ti LDHs structure was verified by appearance of two bands. These two bands overlapped and centered at $2217 \mathrm{~cm}^{-1}$ [29-32]. As can be noted in Figure 4, traces of carbonate anions were also detected by a weak peak at $1459 \mathrm{~cm}^{-1}$ [28]. This weak peak suggests that the IR absorption comes from the carbonates interacting weakly with LDH slabs or just adsorbed on the slab surface. The peak of Ti-OH lattice vibration in the precursor was observed at $669 \mathrm{~cm}^{-1}$ while the $\mathrm{Ni}-\mathrm{OH}$ lattice vibration was $457 \mathrm{~cm}^{-1}[33,34]$.

The effect of the reaction time on the structure of Ni-Ti LDHs was investigated by the comparison between the spectra of the samples formed after $10 \mathrm{~h}$ and $19 \mathrm{~h}$ as shown in Figure 4 . Figure 4a showed that the sample which was formed after $10 \mathrm{~h}$ has the main bands of LDHs structure. By increasing the reaction time, the bands of cyanate and isocyanate anions became sharper and stronger as shown in Figure $4 \mathrm{~b}$. It means that $10 \mathrm{~h}$ is not enough for a complete formation of Ni-Ti LDHs agreeing with XRD results.

\subsection{Thermal Analyses}

The thermal analyses (DTA, TG, and DTG) of Ni-Ti-4 LDHs have used to study the effect of the reaction time on the complete formation of LDHs structure. TG and DTG curves of Ni-Ti LDHs after reaction times $10 \mathrm{~h}$ and $19 \mathrm{~h}$ are displayed in Figure 5. The total mass losses of both samples were similar. Both samples have lost $25 \%$ through four stages. However, the content of both samples was different, where Ni-Ti LDHs after the reaction time $10 \mathrm{~h}$ lost $9.7 \%$ of its mass during the first two stages indicating removal of the surface and the intercalated water. In case of the sample after the reaction time $19 \mathrm{~h}$, the amount of both surface and intercalated water were only $5 \%$. The decomposition of the interlayered cyanate anions happened through the third stage indicating that the content of cyanate anions increased by increasing the reaction time from $12.3 \%$ to $17 \%$. In the final stage, the dehydroxylation process of the nanolayers was gradually achieved up to $600{ }^{\circ} \mathrm{C}$ and was $3 \%$. 


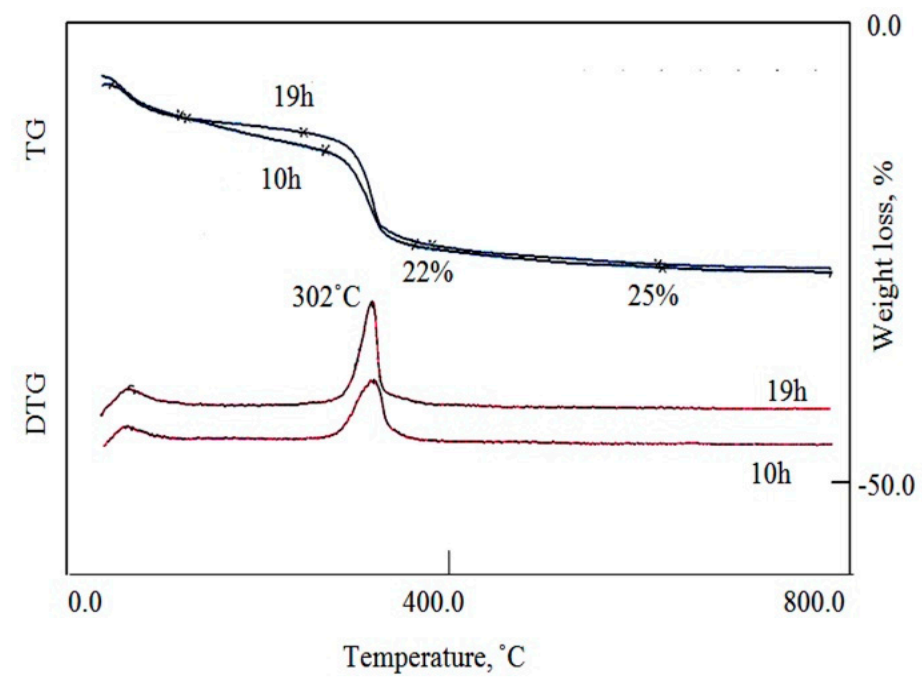

Figure 5. Thermal gravimetric (TG)and Differential thermal gravimetric (DTG) curves of Ni-Ti-4 LDHs at different reaction times.

Figure 6 showed DTA curves for Ni-Ti LDHs after reaction times $10 \mathrm{~h}$ and $19 \mathrm{~h}$. The DTA results confirmed the TG data, where, TG curve of $\mathrm{Ni}$-Ti LDHs after reaction time $10 \mathrm{~h}$ showed one endothermic peak at $302{ }^{\circ} \mathrm{C}$ agreeing with the endothermic and exothermic effects of the removal of the intercalated water and the oxidation of cyanate anions; respectively. The endothermic peak indicates that the heat released from the oxidation reaction is lower than the heat acquired for water removal. It means that the content of cyanate anions is low inside the sample formed after $10 \mathrm{~h}$. In case of the sample formed after $19 \mathrm{~h}$, two exothermic peaks were observed in the DTA curve at $259^{\circ} \mathrm{C}$ and $302^{\circ} \mathrm{C}$ indicating oxidation of cyanate and isocyanate anions. The strong exothermic peak indicates the high content of cyanate anions inside Ni-Ti LDHs after reaction time $19 \mathrm{~h}$.

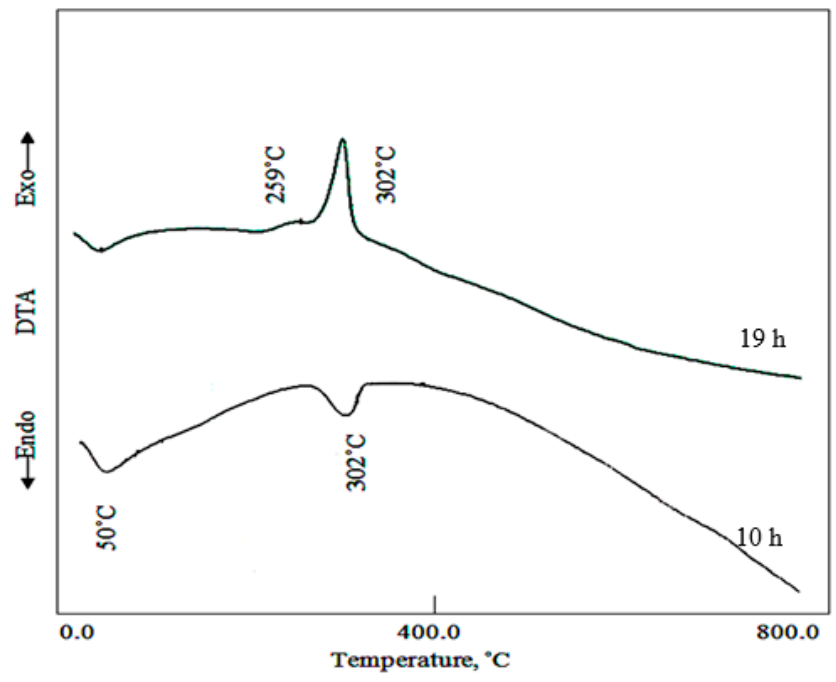

Figure 6. Differential thermal analysis (DTA) curve of Ni-Ti-4 LDHs at different reaction times.

\subsection{Scanning Electron Microscopy}

Scanning electron microscopy of $\mathrm{Ni}$-Ti LDHs with different molar ratios of $\mathrm{Ni}(\mathrm{II})$ and $\mathrm{Ti}(\mathrm{IV})$ were measured after coating the samples with thin layer of platinum to show clear images. Their images are displayed in Figures 7 and 8. 

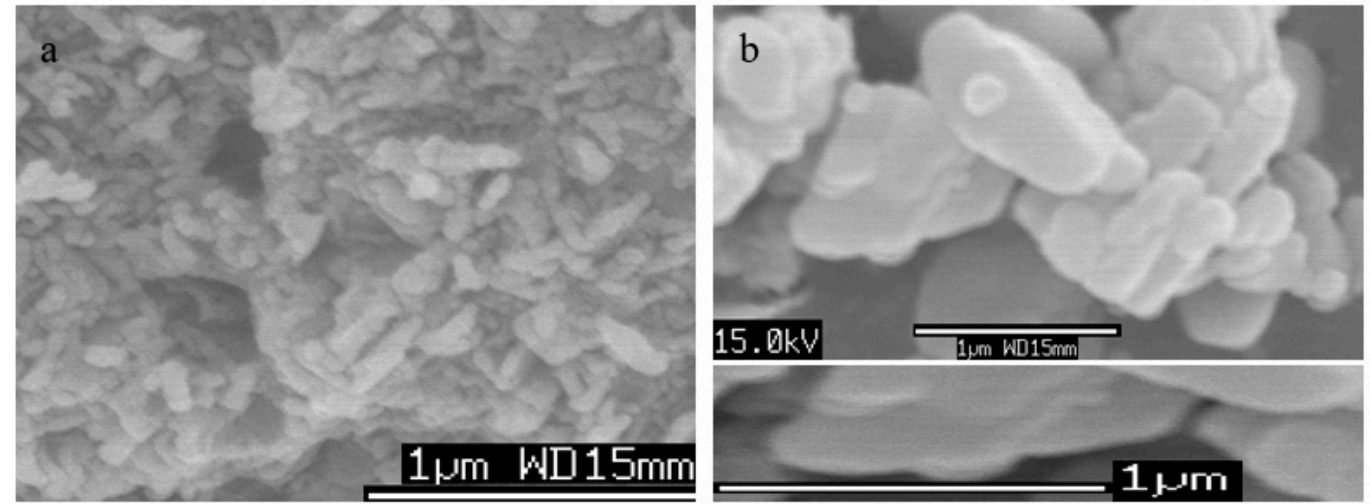

Figure 7. SEM images of Ni-Ti-4 LDHs at different magnification: (a) first location and (b) second location.

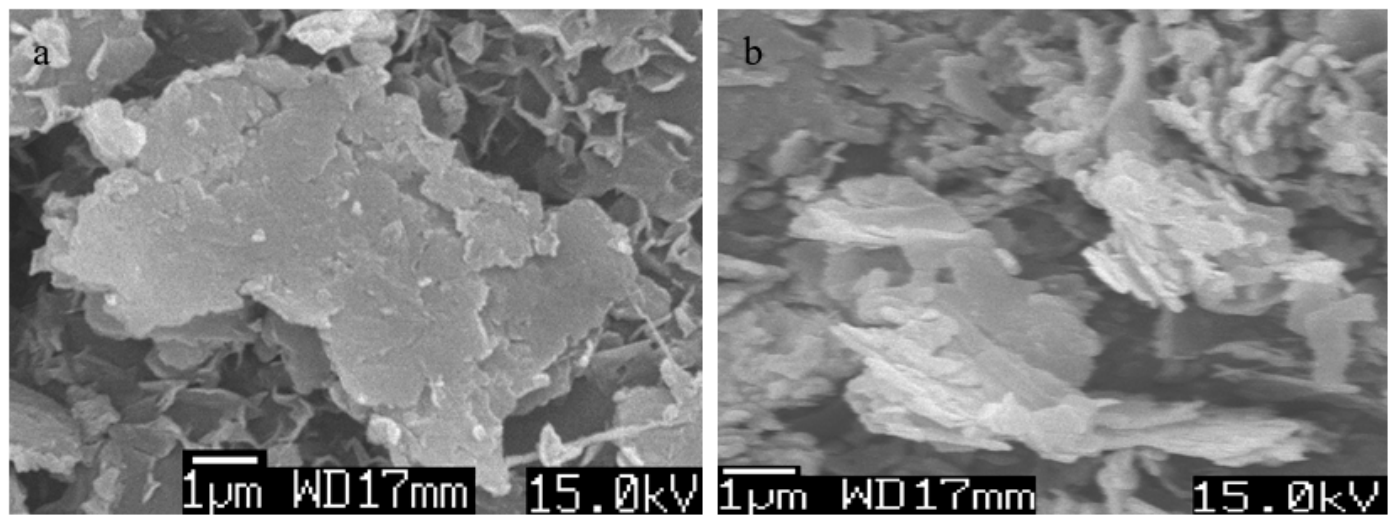

Figure 8. SEM images of (a) Ni-Ti-5 LDHs and (b) Ni-Ti-3 LDHs

Figure 7 showed plate-like morphology for Ni-Ti-4 LDHs with medium ratio of Ni/Ti. Furthermore, it indicated that $\mathrm{Ni}-\mathrm{Ti}$ LDHs contains nanoplatelets having size in the micro scale and thickness in the nano scale. These nanoplatelets built three-dimensional structure of porous system as shown in Figure 7a. By varying the molar ratio of $\mathrm{Ni} / \mathrm{Ti}$, the morphology of $\mathrm{Ni}-\mathrm{Ti} \mathrm{LDHs}$ did not change as shown in Figure 8 . Figure 8 showed platy morphology with irregular geometry for Ni-Ti-5 LDHs and Ni-Ti-3 LDHs.

Although many researchers reported that the nanolayered structure of LDHs is limited to the di- and tri-valent metals, this study has succeeded to prepare LDHs based on tetravalent titanium in addition to nickel metal. According to SEM images, Ti/Ni LDHs have plate-like morphology. These plates consist of several layers. The results of X-ray diffraction and FT-IR allowed building a model for Ti/Ni LDHs as shown in Figure 9. The layer thickness is known from literature as $0.48 \mathrm{~nm}$. It means that the interlayered space available for the anions is in the range of $0.25-0.27$ according to the main interlayered spacing of the XRD patterns. The interlayered cyanate anions among the nanolayers were confirmed by FTIR results. By comparing with the size of cyanate; $0.34 \mathrm{~nm}$, it can intercalate and attack both sides above and below the nanolayers to neutralize the positive charge $(+2)$. In the same time, it makes angle $52.6^{\circ}$ with the nanolayers. The schematic representation of Ti/Ni LDHs is displayed in Figure 9 agreeing with the experimental results.

\subsection{Electrochemical Capacitive Performance of Ti/Ni LDHs}

The electrochemical performance of the all prepared LDHs based electrode were evaluated by the cyclic voltammetry and galvanostatic charge discharge methods and the results are displayed in the Figures 10 and 11. The initial behavior was examined by the CV and the results showed that all the samples have the pseudocapacitive behavior which was confirmed by the presence of the two visible 
peaks in the CV curve. However, the comparative CV curve shows that the optimized LDHs (Ni-Ti-3) exhibited large capacitive area and high capacitance performance as compared to the NiTi-5 LDHs and $\mathrm{Ni}-\mathrm{Ti}-4 \mathrm{LDHs}$. In addition, it means that the proper ratio of Ti/Ni plays an important role for enhancing the overall performance of the samples as shown in Figure 10a. Increasing or decreasing the ratios are significantly reduced the performance of the electrodes. Figure $10 \mathrm{~b}-\mathrm{d}$ shows the $\mathrm{CV}$ profile of the NiTi-5 LDHs, Ni-Ti-4 LDHs, and NiTi-3 LDHs at different scan rate which are further supporting the above comparative results.

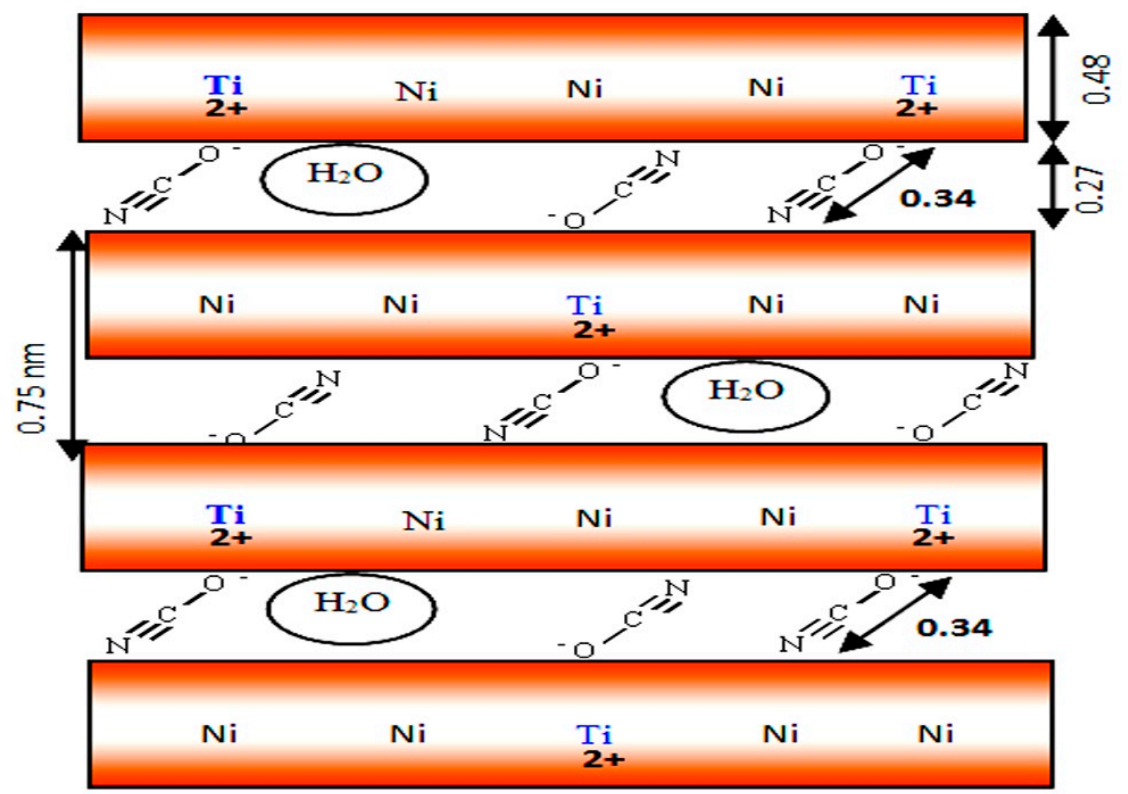

Figure 9. Schematic representation of Ti/Ni LDHs.
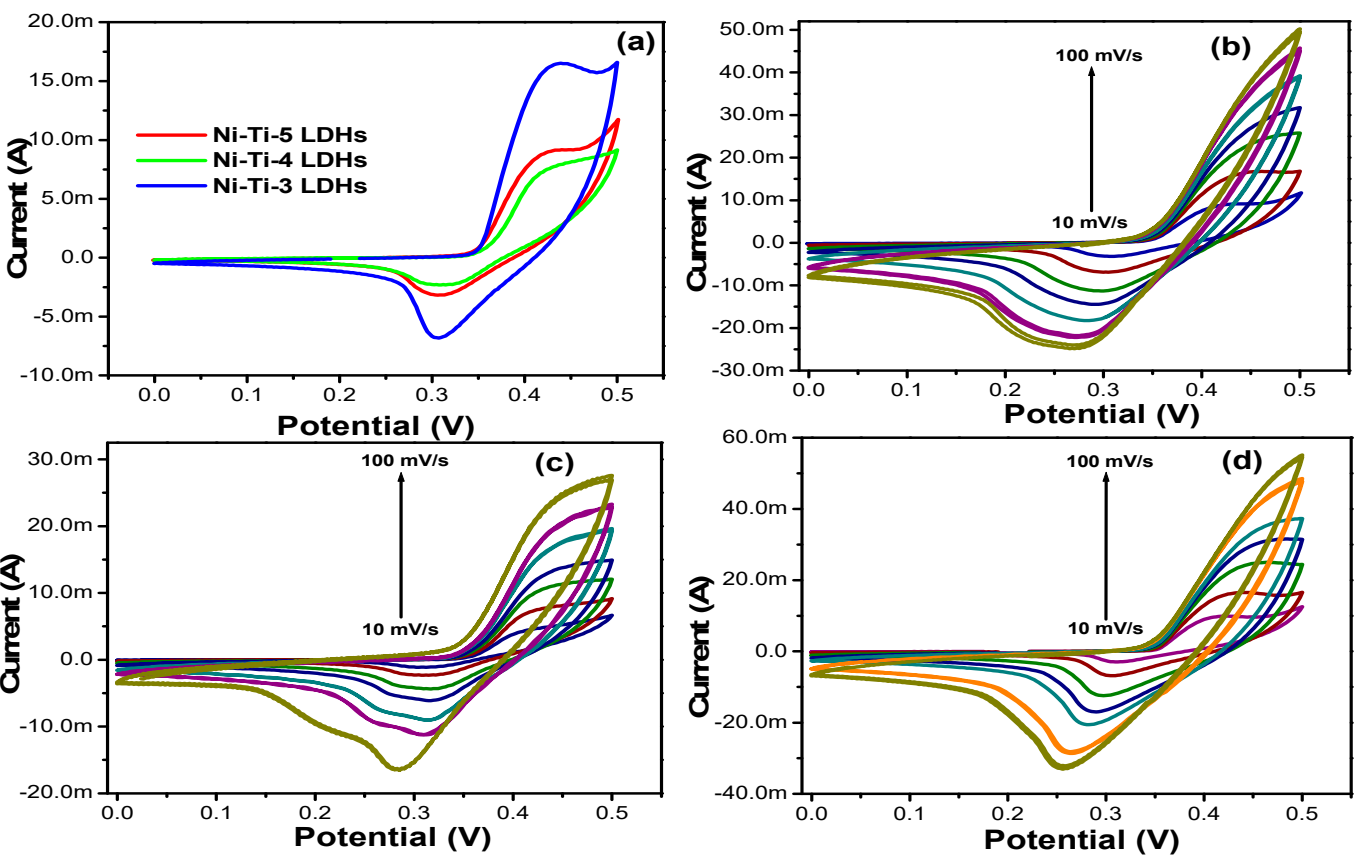

Figure 10. (a) Comparative CV curves of all the LDHs (b) CV curve of the Ni-Ti-5 LDHs (c) CV curve of the Ni-Ti-4 LDHs, and (d) CV curve of the Ni-Ti-3 LDHs at different scan rate. 

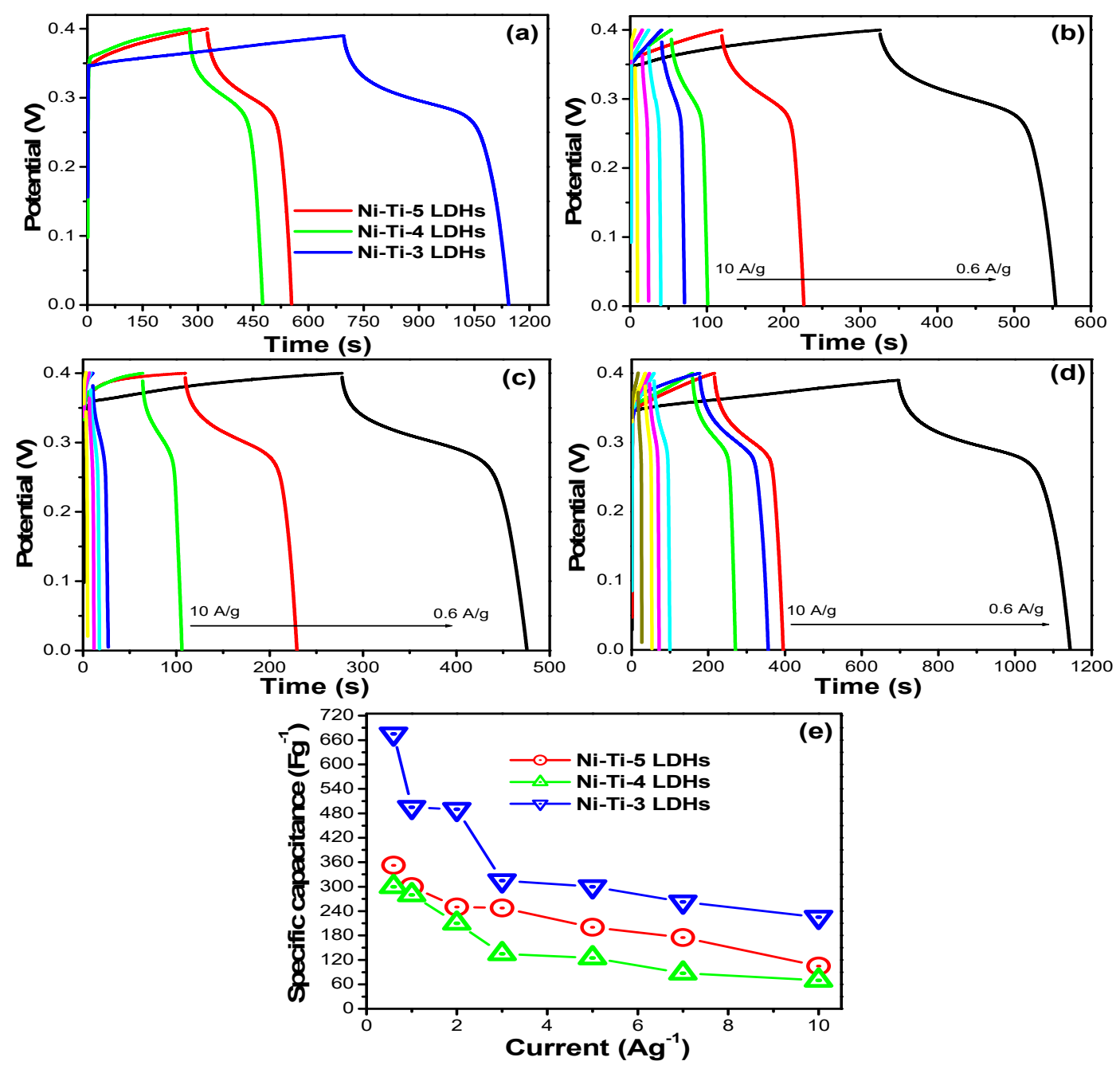

Figure 11. (a) Comparative GCD curves of all the LDHs, (b) GCD curve of the Ni-Ti-5 LDHs (c) GCD curve of the Ni-Ti-4 LDHs, (d) GCD curve of the Ni-Ti-3 LDHs at different current density, and (e) specific capacitance of all the LDHs at different current density.

For the better understanding and for further confirmation of the as prepared LDHs as active material for the electrode applications, the GCD performance was measured and specific capacitance were calculated using the following equations.

$$
C=\frac{I d t}{m d V}
$$

where $C$ is the calculated specific capacitance in $F / g$ and $I$ represent the applied current. The discharge time represent by the " $t$ " and " $m$ " is the mass of the active materials.

Figure 11 shows the comparative GCD curves of all the electrodes at fixed applied potential. This profile was further used to calculate the specific capacitance in which the Ni-Ti-3 LDHs shows the highest capacitance value compared to the other prepared LDHs (Figure 11a). The Ni-Ti-3 LDHs displayed the $675 \mathrm{~F} / \mathrm{g}$ specific capacitance whereas the Ni-Ti-4 LDHs and Ni-Ti-5 LDHs exhibited $300 \mathrm{~F} / \mathrm{g}$ and $352.5 \mathrm{~F} / \mathrm{g}$, respectively. This can be also clearly observed by the graph in which the Ni-Ti-5 LDHs and Ni-Ti-4 LDHs exhibited short charging and discharging time whereas the Ni-Ti-3 LDHs shows the very short charging time but exhibited the longer discharge time. The enhanced performance of the optimized electrode is due to the double layer structure, enough interplanar distance between the layer, and large number of exposed active site within the double layer structure of the LDHs. The specific capacitance of all the electrodes at different current densities was also measured in details 
as shown in Figure 11b-d. The specific capacitance of Ni-Ti-5 LDHs and Ni-Ti-4 LDHs at current load of $0.6,1,2,3,5,7$, and $10 \mathrm{~A} / \mathrm{g}$ were 352.5, 300, 250, 247.5, 200, 175, $105 \mathrm{~F} / \mathrm{g}$ and 300, 290, 210, 135, 125, $87.5,70 \mathrm{~F} / \mathrm{g}$, respectively. The specific capacitance of Ni-Ti-3 LDHs at current load of $0.6,1,2,3,5,7$, and $10 \mathrm{~A} / \mathrm{g}$ were $675,495,490,315,300,262.5$, and $225 \mathrm{~F} / \mathrm{g}$.

Again, we can see that the optimized and perfect ration of the Ti/Ni exhibited the highest specific capacitance compared to the other two electrode materials with different ratio. After the electrochemical capacitive performance was studied by CV and GCD, the cyclic stability of the electrode was further evaluated for further confirmation of LDHs as electrode material for energy storage applications. The repeating charge and discharge cyclic stability test were conducted and results are present in Figure 12, which shows that after 1500 continuous cycle of the charge discharge, the Ni-Ti-3 LDHs maintained the stability and shows excellent capacitance retention up to $85 \%$. The comparative stability graph clearly shows that the as prepared Ni-Ti-3 LDHs retained and maintained good stability, which is further confirming the importance of the as prepared active materials.

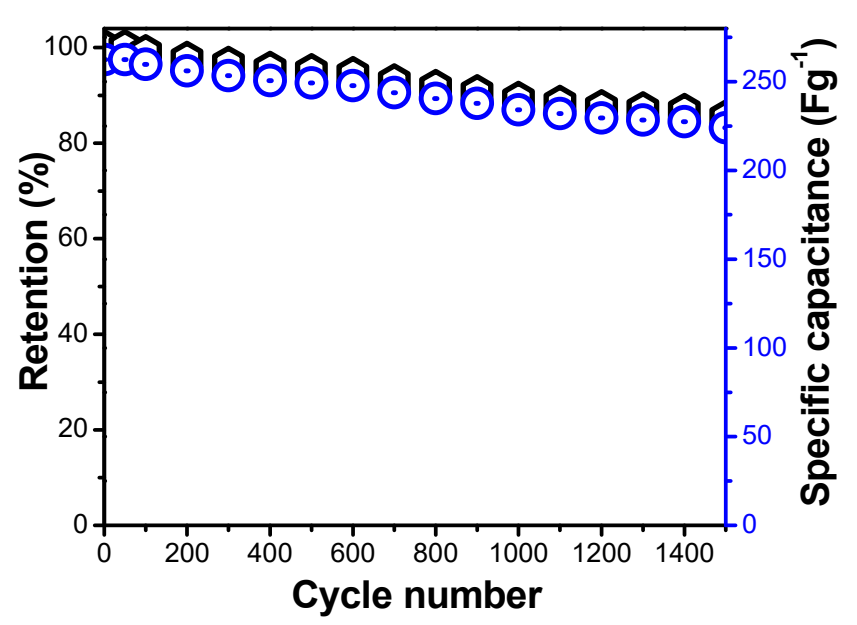

Figure 12. Cyclic performance of the percent of Ni-Ti-3 LDHs in terms of retention and specific capacitance.

\section{Conclusions}

This research achieved a dual aim for optimizing the preparation conditions of Ti/Ni nanolayered structures and producing an active material for the supercapacitor applications. In this trend, series of Ti/Ni based layered double hydroxides (LDHs) with optimized ratio of titanium and nickel have developed through intercalation of cyanate anions using urea hydrolysis. The prepared materials were further characterized by SEM, XRD, TGA, DTA, and FTIR techniques. The performance of LDHs as an active material for the supercapacitor application are also examined in the three electrodes assemble cell and result shows that the Ni-Ti-3 LDHs shows the highest specific capacitance $(675 \mathrm{~F} / \mathrm{g})$ and excellent cyclic retention, compared to the bare material in fixed experimental conditions. The enhanced performance might be the presence of the large number of exposed active site within the double layer stricture of the LDHs, enhanced conductivity, and enough interplanar distance between the layers. These results showed that the prepared LDHs could be the good option for electrode materials for energy storage applications.

Author Contributions: Conceptualization, O.S.; Data curation, O.S. and S.A.A.; Formal analysis, S.A.A. and A.A.; Funding acquisition, O.S.; Investigation, O.S. and A.A.; Methodology, S.A.A.; Project administration, O.S.; Resources, S.A.A.; Software, A.A.; Supervision, O.S.; Validation, A.A.; Visualization, A.A.; Writing-original draft, O.S. and S.A.A.; Writing-review \& editing, O.S. and S.A. All authors have read and agreed to the published version of the manuscript.

Funding: This research was funded by the Deanship of Scientific Research in King Faisal University (Saudi Arabia), grant number 1811006 and The APC was funded by the same grant number 1811006. 
Acknowledgments: The authors acknowledge the Deanship of Scientific Research at King Faisal University for the financial support under the Research Group Support Track (Grant No.1811006).

Conflicts of Interest: The authors declare no conflict of interest.

\section{References}

1. Gunjakar, J.L.; Inamdar, A.I.; Hou, B.; Cha, S.; Pawar, S.M.; Abu, A.T.; Chavan, H.S.; Kim, J.; Cho, S.; Lee, S. Direct growth of 2D nickel hydroxide nanosheets intercalated with polyoxovanadate anions as a binder-free supercapacitor electrode. Nanoscale 2018, 10, 8953-9412. [CrossRef]

2. Nagaraju, C.; Gopi, C.V.; Ahn, J.W.; Kim, H.J. Hydrothermal synthesis of MoS2, WS2 nanoparticles for high-performance supercapacitor applications. New J. Chem. 2018, 42, 12357-12360. [CrossRef]

3. Lim, A.C.; Jadhav, H.S.; Seo, J.G. Electron transport shuttle mechanism via Fe-N-C bond derived from a conjugated microporous polymer for a supercapacitor. Dalton Trans. 2018, 47, 852-858. [CrossRef]

4. Yi, H.; Wang, H.; Jing, Y.; Peng, T.; Wang, Y.; Guo, J.; He, Q.; Guo, Z.; Wang, X. Advanced asymmetric supercapacitors based on $\mathrm{CNT} @ \mathrm{Ni}(\mathrm{OH})_{2}$ core-shell composites and 3D graphene networks. J. Mater. Chem. A 2015, 3, 19545-19555. [CrossRef]

5. Saddique, J.; Cheng, X.; Shi, H.; Wu, R.; Zhang, Y. High-performance Ni-Co sulfide nanosheet-nanotubes grown on Ni Foam as a binder free electrode for supercapacitors. Appl. Sci. 2019, 9, 3082. [CrossRef]

6. Lyu, H. Triple layer tungsten trioxide, graphene, and polyaniline composite films for combined energy storage and electrochromic applications. Polymers 2020, 12, 49. [CrossRef] [PubMed]

7. Ansari, S.A.; Parveen, N.; Kotb, H.M.; Alshoaibi, A. Hydrothermally derived three-dimensional porous hollow double-walled $\mathrm{Mn}_{2} \mathrm{O}_{3}$ nanocubes as superior electrode materials for supercapacitor applications. Electrochim. Acta 2020, 335, 136783. [CrossRef]

8. Parveen, N.; Hilal, M.; Han, J.I. Newly design porous/sponge red phosphorus@graphene and highly conductive $\mathrm{Ni}_{2} \mathrm{P}$ electrode for asymmetric solid state supercapacitive device with excellent performance. Nano-Micro Lett. 2020, 12, 1-16. [CrossRef]

9. Parveen, N.; Abdullah, A.; Han, J.I. Robust cyclic stability and high-rate asymmetric supercapacitor based on orange peel-derived nitrogen-doped porous carbon and intercrossed interlinked urchin-like NiCo2O4@3DNF framework. Electrochim. Acta 2019, 293, 84-96. [CrossRef]

10. Liu, T.; Zhang, L.; Cheng, B.; You, W.; Yu, J. Fabrication of a hierarchical NiO/C hollow sphere composite and its enhanced supercapacitor performance. Chem. Commun. 2018, 54, 3731-3734. [CrossRef]

11. Huang, Y.Y.; Lin, L.Y. Synthesis of ternary metal oxides for battery-supercapacitor hybrid devices: Influences of metal species on redox reaction and electrical conductivity. ACS Appl. Energy Mater. 2018, 1, 2979-2990. [CrossRef]

12. Ding, X.B.; Zhu, J.S.; Hu, G.Z.; Zhang, S.Q. Core-shell structured CoNi2S4@polydopamine nanocomposites as advanced electrode materials for supercapacitors. Ionics 2019, 25, 897-901. [CrossRef]

13. Wang, L.; Chen, B.; Ma, J.; Cui, G.; Chen, L. Reviving lithium cobalt oxide-based lithium secondary batteries-toward a higher energy density. Chem. Soc. Rev. 2018, 47, 6505-6602. [CrossRef] [PubMed]

14. Fic, K.; Platek, A.; Piwek, J.; Frackowiak, E. Sustainable materials for electrochemical capacitors. Mater. Today 2018, 21, 437-454. [CrossRef]

15. Nguyen, T.; Montemor, M.D.F. Metal Oxide and Hydroxide-Based Aqueous Supercapacitors: From Charge Storage Mechanisms and Functional Electrode Engineering to Need-Tailored Devices. Adv. Sci. 2019, 6, 1801797. [CrossRef]

16. Liu, T.; Zhang, L.; You, W.; Yu, J. Core-Shell Nitrogen-Doped Carbon Hollow Spheres/Co3O4 Nanosheets as Advanced Electrode for High-Performance Supercapacitor. Small 2018, 14, 1702407. [CrossRef] [PubMed]

17. Zhu, J.S.; Zhang, S.Q.; Wang, D.L. Facile fabrication of coal derived activated carbon/Co3O4 nanocomposites with superior electrochemical performance. Ionics 2017, 23, 1927-1931. [CrossRef]

18. Yang, Y.; Xia, X.; Ye, H.; Wang, L.; Jiao, X.; Lei, W.; Hao, Q. Three-Dimensional Hierarchical Structure ZnO@C@NiO on Carbon Cloth for Asymmetric Supercapacitor with Enhanced Cycle Stability. ACS Appl. Mater. Interfaces 2018, 10, 3549-3561. [CrossRef] 
19. Zhao, J.; Li, Z.; Yuan, X.; Yang, Z.; Zhang, M.; Meng, A.; Li, Q. A High-Energy Density Asymmetric Supercapacitor Based on Fe2O3 Nanoneedle Arrays and NiCo2O4/Ni(OH)2 Hybrid Nanosheet Arrays Grown on SiC Nanowire Networks as Free-Standing Advanced Electrodes. Adv. Energy Mater. 2018, 8, 1702787. [CrossRef]

20. Lin, J.; Jia, H.; Liang, H.; Chen, S.; Cai, Y.; Qi, J.; Qu, C.; Cano, J.; Fei, W.; Feng, J. Hierarchical CuCo2S4@NiMn-layered double hydroxide core-shell hybrid arrays as electrodes for supercapacitors. Chem. Eng. J. 2018, 336, 562-569. [CrossRef]

21. Zhou, P.; Wang, C.; Liu, Y.; Wang, Z.; Wang, P.; Qin, X.; Zhang, X.; Dai, Y.; Whangbo, M.H.; Huang, B.B. Sulfuration of NiV-layered double hydroxide towards novel supercapacitor electrode with enhanced performance. Chem. Eng. J. 2018, 351, 119-126. [CrossRef]

22. Malak-Polaczyk, A.; Vix-Guterl, C.; Frackowiak, E. Carbon/layered double hydroxide (LDH) composites for supercapacitor application. Energ. Fuel 2010, 24, 3346-3351. [CrossRef]

23. Xiao, Y.; Su, D.; Wang, X.; Wu, S.; Zhou, L.; Sun, Z.; Wang, Z.; Fang, S.; Li, F. Ultrahigh energy density and stable supercapacitor with 2D NiCoAl layered double hydroxide. Electrochim. Acta 2017, 253, $324-332$. [CrossRef]

24. Jagadale, A.D.; Guan, G.; Li, X.; Du, X.; Ma, X.; Hao, X.; Abudula, A. Ultrathin nanoflakes of cobalt-manganese layered double hydroxide with high reversibility for asymmetric supercapacitor. J. Power Sources 2016, 306, 526-534. [CrossRef]

25. Shao, M.; Zhang, R.; Li, Z.; Wei, M.; Evans, D.G.; Duan, X. Layered double hydroxides toward electrochemical energy storage and conversion: Design, synthesis and applications. Chem. Commun. 2015, 51, 15880-15893. [CrossRef] [PubMed]

26. Bao, W.; Tian, H.; Jiang, Y.; Zhu, K.; Zhang, R.; Tan, Y.; Li, W.; Yu, Z.; Wang, L. Controlled preparation of Ni-Al $\mathrm{LDH}-\mathrm{NO} 3$ by a dual-anion intercalating process for supercapacitors. Ionics 2019, 25, 3859-3866. [CrossRef]

27. Li, Y.; Shan, L.; Sui, Y.; Qi, J.; Wei, F.; He, Y.; Meng, Q.; Ren, Y.; Liu, J. Ultrathin Ni-Co LDH nanosheets grown on carbon fiber cloth via electrodeposition for high performance supercapacitors. J. Mater. Sci. Mater. Electron. 2019, 30, 13360-13371. [CrossRef]

28. Saber, O.; Hefny, N.; AlJaafari, A.A. Improvement of physical characteristics of petroleum waxes by using nano-structured materials. Fuel Process. Technol. 2011, 92, 946-951. [CrossRef]

29. Nakamoto, N. Infrared and Raman Spectra of Inorganic and Coordination Compounds, 4th ed.; Wiley: New York, NY, USA, 1986.

30. Saber, O.; Shaalan, N.M.; Osama, A.; Alshoaibi, A. Development of the morphology and the band gap energy of $\mathrm{Co}-\mathrm{Si}$ nanofibers by inserting zirconium and titanium with dual anions intercalation process. Appl. Sci. 2019, 9, 4775-4789. [CrossRef]

31. Faramawy, S.; Zaki, T.; Sakr, A.A.E.; Saber, O.; Aboul-Gheit, A.K.; Hassan, S.A. The activity of Mg-Al layered double hydroxides intercalated with nitrogencontaining anions towards the removal of carbon dioxide from natural gas. J. Nat. Gas Sci. Eng. 2018, 54, 72-82. [CrossRef]

32. Saber, O.; Aljaafari, A.; Alomair, H.A.; Alshoaibi, A. Novel strategy for producing nanoplatelets to be used as building blocks for shaping nanofibers through layered double hydroxides and poly vinyl alcohol. Chem. Sel. 2019, 4, 4293-4300. [CrossRef]

33. Hu, L.; Gao, W.; He, J.; Liu, H.; Li, B.; Zhang, X.M. Ni-Al-Ti-layered double hydroxide intercalated with beta-CD and CM-beta-CD: Interaction between the interlayer guests and the laminates. J. Mol. Struct. 2013, 1041, 151-155. [CrossRef]

34. Saber, O.; Aljaafari, A.; Alshoaibi, A.; Al-Yaari, M.; Osama, M. A novel route for controlling and improving the texture of porous structures through dual growth of alumina nanoparticles and carbon nanotubes using explosion process of solid fuel. J. Mater. Res. Technol. 2020, 9, 67-75. [CrossRef]

(C) 2020 by the authors. Licensee MDPI, Basel, Switzerland. This article is an open access article distributed under the terms and conditions of the Creative Commons Attribution (CC BY) license (http://creativecommons.org/licenses/by/4.0/). 